\title{
Ventajas diagnósticas de convertir nuestro móvil en una cámara termográfica
}

\author{
Diagnostic advantages of turning our smartphone into a \\ thermal imaging camera
}

\section{A. Ortega Romero}

\begin{abstract}
Servicio de Anestesiología. Hospital ASEPEYO-Coslada. Coordinador de la Unidad del Dolor Crónico. Coslada, Madrid, España
\end{abstract}

El calor y la temperatura han estado vinculados a la historia humana desde sus orígenes; de hecho, en muchas áreas y actividades diarias, uno de los primeros síntomas que revela la existencia de una anomalía o irregularidad es la variación habitual de temperatura. En 1800, William Herschel descubrió los rayos infrarrojos, y unos años después, en 1840, su hijo John Herschel capturó el primer "termograma". En el siglo $x x$ el desarrollo tecnológico de la termografía (TI) surge de sus aplicaciones en el ámbito militar, y sobre todo del campo de la construcción detectando anomalías en el estado de las edificaciones.

En medicina, la TI comenzó a usarse en los años 60, pero debido a los malos resultados como herramienta diagnóstica y la falta de protocolos estandarizados, se dejó de utilizar en detrimento de otras técnicas más precisas (1). No obstante, las mejoras tecnológicas de la Tl en los últimos años y sus ventajas (no invasiva, rápida, dinámica, sin efectos secundarios] han hecho posible un resurgimiento de la misma. Entre las nuevas aplicaciones podemos destacar las que se desarrollan en el ámbito de la actividad física y el deporte, cuantificando la asimilación de la carga de trabajo físico, la valoración de la condición física, la prevención y el seguimiento de las lesiones a través de algoritmos y software que proporcionan métricas específicas de los deportistas tras el análisis de las imágenes de termografía [2].

En el área de dolor se han realizado varios estudios sobre la utilidad de la TI en el síndrome de dolor regional complejo (SDRC), neuralgia posherpética, lesión por latigazo cervical, artritis inflamatoria, articulación temporo-mandibular, cefalea y síndrome de dolor miofascial. En todos estos trabajos se han utilizado cámaras termográficas de alta resolución y de alto coste económico [3].

Recientemente se han comercializado cámaras termográficas basadas en teléfonos móviles que han sido probadas y validadas para biomedicina [4]. El estudio de Dhatt y cols. [5] aplica una de estas cámaras para el diagnóstico y tratamiento del SDRC.

El diagnóstico del SDRC es un desafío debido a la amplia variabilidad de sus manifestaciones clínicas. Los criterios de consenso de Budapest son el enfoque diagnóstico más aceptado en la actualidad. Existe un acuerdo unánime sobre el diagnóstico y tratamiento precoz del dolor y la rehabilitación como medida más eficaz para el pronóstico funcional del SDRC. Sin embargo, especialmente en etapas tan tempranas, la implementación de medidas funcionales objetivamente cuantificables puede ser extremadamente útil para el diagnóstico precoz, la clasificación de la gravedad de los síntomas y el seguimiento de la respuesta al tratamiento del SDRC.

En el trabajo de Dhatt y cols. (5) se destaca la sensibilidad y especificidad de las imágenes logradas por estas cámaras termográficas basadas en el móvil para apoyar el diagnóstico clínico inicial del SDRC, monitorizar la respuesta al tratamiento médico con prednisona y demostrar la eficacia de los bloqueos nerviosos diagnósticos. Se ilustra con imágenes de cada caso clínico la normalización de la asimetría térmica después de cada intervención o tratamiento realizado en cada paciente.

La sensibilidad de las pruebas realizadas podría haberse mejorado si hubiera aplicado una prueba de estrés por frío como las realizadas por Pérez-Concha y cols. (6) y aplicando protocolos cuantitativos que atenúen los factores de influencia extrínsecos.

Estas cámaras termográficas en el móvil tienen un coste mucho menor y permitirán tener acceso a esta tecnología a un mayor número de profesionales. La mejora continua en la resolución de estas cámaras y el procesamiento en los dispositivos móviles lograrán en un futuro reciente mejorar su precisión y sensibilidad. Aún son necesarios más trabajos para validar y aumentar la eficacia diagnóstica de la TI en el dolor. Previsiblemente la accesibilidad de las cámaras termográficas en nuestros teléfonos móviles despertará el interés de muchos profesionales implicados en el tratamiento del 
dolor aumentando el nivel de evidencia de esta técnica. El análisis cuantitativo de la variables térmicas con nuevos programas informáticos que apliquen coeficientes de variación nos darán mayor validez a todas la imágenes obtenidas y podremos realizar rápidos informes de seguimiento de las asimetrías encontradas [7].

\section{BIBLIOGRAFÍA}

1. Ring EF, Ammer K. Infrared thermal imaging in medicine. Physiol Meas. 2012;33(3):R33-46. DOI: 10.1088/09673334/33/3/R33

2. Prieto Quesada Jl. Application of infrared thermography in sports science. Valencia, Spain; Ed Springer; 2017.

3. Nahm FS. Infrared thermography in pain medicine. Korean J Pain. 2013;26(3):219-22. DOI: 10.3344/ kjp.2013.26.3.219.
4. Kirimtat A, Krejcar O, Selamat A, Herrera-Viedma E. FLIR vs SEEK thermal cameras in biomedicine: comparative diagnosis through infrared thermography. BMC Bioinformatics. 2020;21(Suppl 2):88. DOI: 10.1186/s12859-020-3355-7.

5. Dhatt S, Krauss EM, Winston P. The Role of FLIR ONE Thermography in Complex Regional Pain Syndrome: A Case Series. Am J Phys Med Rehabil. 2021;100(4):e48-e51. DOI: 10.1097/PHM.0000000000001522

6. Pérez-Concha T, Tijero B, Acera M, Fernández T, Gabilondo I, Gómez-Esteban JC. Usefulness of thermography in the diagnosis and classification of complex regional pain syndrome. Neurologia. 2020:S0213-4853(20)30337-6. DOI: 10.1016/j.nrl.2020.10.011.

7. Requena-Bueno L, Priego-Quesada Jl, Jimenez-Perez I, Gil-Calvo M, Pérez-Soriano P. Validation of ThermoHuman automatic thermographic software for assessing foot temperature before and after running. J Therm Biol. 2020;92:102639. DOI: 10.1016/j.jtherbio.2020.102639 